\title{
Understanding the principles of ethics in health care: a systematic analysis of qualitative information
}

\author{
Vanishree M. Kemparaj ${ }^{1}$, Umashankar G. Kadalur ${ }^{2 *}$
}

\begin{abstract}
Department of Public Health Dentistry, ${ }^{1}$ Maaruthi Dental College, Bangalore/ Rajiv Gandhi University of Health Sciences, ${ }^{2}$ MR Ambedkar dental college, Bangalore/ Rajiv Gandhi University of Health Sciences, Bangalore, Karnataka, India
\end{abstract}

Received: 30 December 2017

Accepted: 01 February 2018

\author{
*Correspondence: \\ Dr. Umashankar G Kadalur, \\ E-mail: drumashankargk@yahoo.com
}

Copyright: () the author(s), publisher and licensee Medip Academy. This is an open-access article distributed under the terms of the Creative Commons Attribution Non-Commercial License, which permits unrestricted non-commercial use, distribution, and reproduction in any medium, provided the original work is properly cited.

\begin{abstract}
Despite incorporating ethical teaching in medical curricula there is paucity in knowledge of ethics among our practitioners. To improve the ethical knowledge it is important to understand the ethical issues or challenges encountered in the present scenario. The issues encountered by the health professionals helps to understand how the ethical principles are in day to today practice. Empirical researches have shown that qualitative research brings research closer to decision making. Hence data obtained from peer-reviewed qualitative articles were used for assessing ethical principles in every day practice by health professional. The studies have shown that autonomy, beneficence, justices are some of the principles health professionals consider before taking the decisions in health care.
\end{abstract}

Keywords: Ethics, Health care, Qualitative research, Informed consent

\section{INTRODUCTION}

All health care professionals have an obligation for the duty of care in alleviating pain and minimize suffering. Thus every action taken by the doctor or health care professional constitute ethical and moral dimension. This is guided by the set of ethical principles aimed at improving the quality of patient care by identifying, analysing and attempting to resolve any issues arising in practice. According to Beauchamp and Childress, no one principle is higher than other and depends on the context of given situation. Beauchamp and Childress consider the four principles as prima facie binding, i.e. they must be fulfilled, unless they conflict on a particular occasion with an equal or stronger principle. ${ }^{1}$

In the past clinical ethics was intended to be defined by the clinical area that focused on for instance, end of life care, consent, priority setting or women's health. Despite incorporating ethical teaching in medical curricula there is paucity in knowledge of ethics among our practitioners. Recognizing the importance of ethics in health care practice the MCI and DCI has prescribed the teaching hours of ethics to more at under graduate level. To improve the ethical knowledge it is important to understand the ethical issues or challenges encountered in the present scenario. A thorough review of literature would help us understand the dilemmas and help to us formulate better research in this regard.

Empirical research have shown that the evidence that quantitative methods alone is not sufficient since phenomena examined by ethics researchers are deeply entwined into the fabric of professions, organizations and human lives. Hence qualitative methods have begun to play its role. Empirical studies exploring the ethical dimension of the physician practice mainly rely on 
interview, focus group discussion and observation of clinical practice. The systematic review in this regard is an important tool for the evidence based medicine and practice which aims to bring research closer to decision making. ${ }^{2-7}$

In this systematic review an attempt has been made to review articles which emphasize on research which prioritizes the daily activities of the doctor within the clinical encounter rather than on the research which emphasize life threatening and emergency situation.

\section{METHODS}

\section{Collection of data sources}

To identify a comprehensive data search, different strategies used for identifying qualitative research papers in area of health care ethics was used. It included "Semantic" based strategies, thesaurus, free text terms relevant to qualitative research and "broad-based" terms such as interview, focus group discussion, qualitative research and also using citation in health care ethics. Articles were searched in medical, dental, nursing and social science literature. Choosing of the article aimed to include all relevant studies related to ethical issues in healthcare ethics.
Only peer-reviewed articles pertaining to qualitative studies in health care ethics and which were published in English literature were included. Thus there were 34 research articles pertaining to the review in focus.

Data extraction was done. After verification of a study's eligibility for inclusion in the review; study details such as name of the study, authors, journal, research design used, data collection, data analysis methods, results and conclusion were determined by the researcher and included in the final analysis by all the authors.

\section{Data analysis}

For data analysis guidelines for critical review form for qualitative studies developed by the McMaster University Occupational Therapy was followed. ${ }^{4}$

\section{RESULTS}

There were 10 relevant qualitative studies collecting the data regarding the ethical issues in health care practice. The studies were related to use of ethical principles such as autonomy, informed consent, beneficiance, nonbeneficiance, and justice in health care decision making.

Table 1: Showing the ethical dilemmas faced by the research participants in different research studies.

\begin{tabular}{|c|c|c|c|}
\hline & Author/ year & Themes & Responses \\
\hline \multirow{3}{*}{1.} & \multirow{3}{*}{$\begin{array}{l}\text { Torjuul, Nordam, } \\
\text { Sørlie }\end{array}$} & Respecting patients & $\begin{array}{l}\text { "I cannot remove any parts of a person's body unless they are } \\
\text { accountable; unless they themselves comprehend that it is necessary". }\end{array}$ \\
\hline & & $\begin{array}{l}\text { Resolving } \\
\text { differences in } \\
\text { opinions }\end{array}$ & $\begin{array}{l}\text { "Sometimes you are asked to do something you do not think is right. } \\
\text { You are for instance asked to do things in a particular way, and then you } \\
\text { think that it is difficult to go against the decisions of those who are more } \\
\text { experienced. It does not need to be anything strictly right or wrong, but } \\
\text { minor things, like you would have chosen another type of drug". }\end{array}$ \\
\hline & & $\begin{array}{l}\text { Incompetent } \\
\text { colleagues }\end{array}$ & $\begin{array}{l}\text { "On the one hand you realize that surgery is complicated, and you } \\
\text { cannot blame people for a single decision or a single action that is } \\
\text { wrong". }\end{array}$ \\
\hline \multirow{3}{*}{2} & \multirow{3}{*}{ Ebbesen et al } & beneficence & $\begin{array}{l}\text { We are employed here to produce drugs for the benefit of the patients, } \\
\text { so we have to see things in a broader perspective... of course, that is not } \\
\text { where your focus is when you are about to clone something and } \\
\text { considering what restriction sites to apply. At that moment, the overall } \\
\text { perspective is not the focus of your attention, but you have to keep it in } \\
\text { the back of your mind as part of your daily activities in order for things } \\
\text { to make sense in the end. }\end{array}$ \\
\hline & & $\begin{array}{l}\text { Autonomy } \\
\text { Informed consent }\end{array}$ & $\begin{array}{l}\ldots \text { if you were a seriously ill or terminally ill patient, I think I would } \\
\text { accept just about any treatment, because you would accept the risk } \\
\text { involved. }\end{array}$ \\
\hline & & $\begin{array}{l}\text { Justice } \\
\text { Just distribution }\end{array}$ & $\begin{array}{l}\text { Resources are scarce and the number of patients in need of radiotherapy } \\
\text { is increasing... you have so many patients } \\
\text { and you want to be able to cure as many as possible from their cancer, } \\
\text { which is, after all, the main problem. But } \\
\text { what is the best way to do it so that the patients become most well- } \\
\text { functioning afterwards, cosmetically and } \\
\text { functionally? }\end{array}$ \\
\hline
\end{tabular}




\begin{tabular}{|c|c|c|c|}
\hline & Author/ year & Themes & Responses \\
\hline \multirow[b]{2}{*}{3} & \multirow[b]{2}{*}{ Jafarey, Farooqui } & Information & $\begin{array}{l}\text { Most participants agreed that it was perfectly acceptable to use } \\
\text { alternative words like "growth" or "mass" rather than use the term } \\
\text { "cancer" and this did not amount to deception. }\end{array}$ \\
\hline & & Apprehensions & $\begin{array}{l}\text { "I try and tell the patient all possible complications of a procedure so } \\
\text { that if something does go wrong, at least he was forewarned. I however } \\
\text { tend to loose patients also by this approach as they sometimes choose to } \\
\text { go to a surgeon who does not alarm them with all the possibilities". }\end{array}$ \\
\hline \multirow{2}{*}{4} & \multirow{2}{*}{ Hurst, et al } & $\begin{array}{l}\text { Looking for } \\
\text { assistance }\end{array}$ & $\begin{array}{l}\text { When facing the ethical difficulties they described, most of the } \\
\text { respondents looked for assistance. This could come from persons } \\
\text { involved with the patient, or from persons trusted by the respondent for } \\
\text { other reasons. }\end{array}$ \\
\hline & & Avoiding conflict & $\begin{array}{l}\text { An example in which avoidance of conflict meant not facing it is } \\
\text { illustrated in the following situation. In this case, deception was used: } \\
\text { the respondent did what he thought was right, and pretended to the } \\
\text { patient's family that he had done what they thought was right. }\end{array}$ \\
\hline \multirow[t]{3}{*}{5} & \multirow[t]{3}{*}{ Agledahl, et al } & Break down & 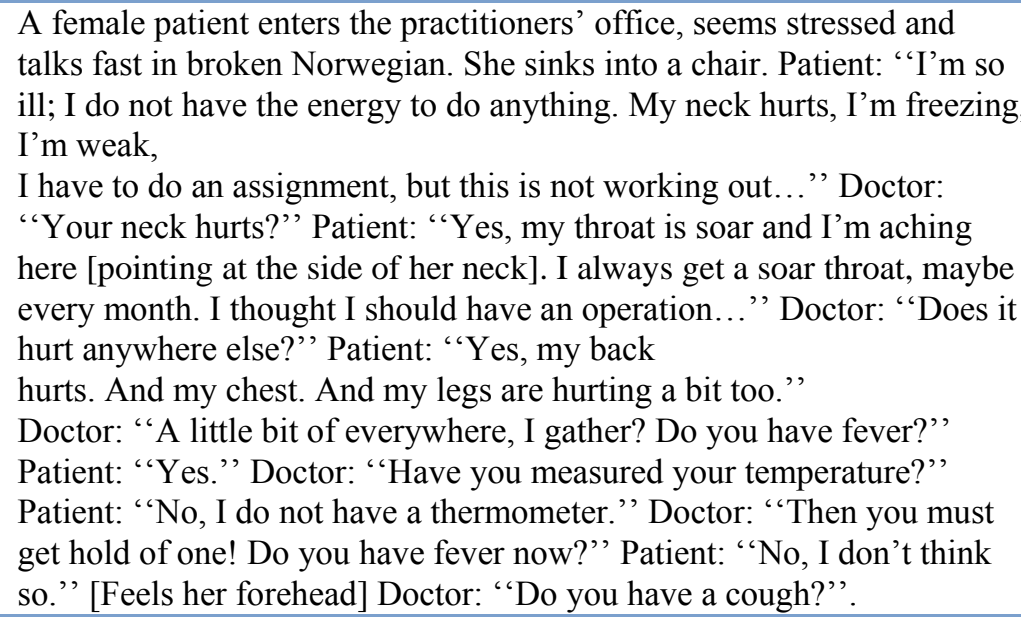 \\
\hline & & Concretizing & $\begin{array}{l}\text { Doctor I: She has been admitted for rehabilitation. She is poorly } \\
\text { mobilized and nourished, and she is low in albumin. Nurse: Is she the } \\
\text { one with the black toes? } \\
\text { Doctor II: They are not black; they are poorly circulated. } \\
\text { Doctor I: We have to at least mobilize her into a chair. Doctor II: She } \\
\text { also has diarrhoea and a positive Hemofec. It is somewhat hard to } \\
\text { interpret. But judging her blood values, everything looks better. }\end{array}$ \\
\hline & & Categorizing & $\begin{array}{l}\text { Interviewer: "Your first patient today mentioned that she had } \\
\text { discomfort in her chest. What were your thoughts about that?" Doctor: } \\
\text { "She brought it up somewhat late in the consultation and I was } \\
\text { beginning to run out of time. It didn't sound that serious, and it wasn't } \\
\text { anything acute, she had had it for several years. I could have taken a } \\
\text { spirometry of course... Most likely it is muscular, she is sitting quite } \\
\text { tense, like this." }\end{array}$ \\
\hline \multirow[t]{2}{*}{6} & \multirow[t]{2}{*}{ Rosenbaum, et al } & $\begin{array}{l}\text { Concern over } \\
\text { telling the truth, }\end{array}$ & $\begin{array}{l}\text { "The biopsy came back that he had lung cancer... our attending wanted } \\
\text { to wait until his primary } \\
\text { attending came back a week later before telling him. We... myself and } \\
\text { my intern, felt very uncomfortable waiting } \\
\text {... he [the patient] kept asking us, 'Do you know the results?'... and } \\
\text { we'd have to tell him... 'we're waiting for the results.' Even though we } \\
\text { knew." }\end{array}$ \\
\hline & & Preventing harm, & $\begin{array}{l}\text { "It felt difficult for us to live with the fact that we had done something } \\
\text { to her that had killed her... Sometimes I just feel really evil. Doing } \\
\text { things to people. That's my way of saying it. But I feel, a lot of times, } \\
\text { we do different procedures to people that are-putting in lines or } \\
\text { whatever-in their so-called best interest. I just wonder a lot of times } \\
\text { whether it really is." }\end{array}$ \\
\hline
\end{tabular}




\begin{tabular}{|c|c|c|c|}
\hline & Author/ year & Themes & Responses \\
\hline & & $\begin{array}{l}\text { Managing the limits } \\
\text { of one's } \\
\text { competence }\end{array}$ & $\begin{array}{l}\text { “... I'm transferring them [a patient] to somebody and meeting } \\
\text { resistance, just feeling uncomfortable because they [co-resident] say, } \\
\text { 'why didn't you do this?' or 'why didn't you do that?' or 'they're not } \\
\text { really appropriate for me right now. You called me too soon.' Just } \\
\text { feeling like I'd been inadequate, inadequately working up the patient } \\
\text { and why would I call them prematurely. I feel that, actually, a lot.” }\end{array}$ \\
\hline \multirow[t]{2}{*}{8} & \multirow[t]{2}{*}{ Braunack-Mayer } & Accessibility & $\begin{array}{l}\text { Dr Newton: I felt I looked after them [these patients who were elderly], } \\
\text { to the best of my ability, in fact } \\
\text { Extremely well. And at times I'd put myself out a lot-not just a little } \\
\text { bit-but a lot, on individual instances, and that had always been } \\
\text { appreciated, or seemed to have been appreciated. And yes, I'll give you } \\
\text { some beautiful examples. Some of these home visits I did when I went } \\
\text { to pick the gentleman who had fallen often onto his wife, and couldn't } \\
\text { move, I went because nobody else would go, and the family wouldn't } \\
\text { go. The family said, no, get the doctor. And when I got there all I } \\
\text { actually had to do was get him back on his feet, and make sure that they } \\
\text { were all right. And that would happen, at virtually any hour of the day } \\
\text { or night. They would ring, but I went. Well, I always went myself, and I } \\
\text { never sent a locum ... That's going beyond the call of duty, on the } \\
\text { whole. }\end{array}$ \\
\hline & & comprehensiveness & $\begin{array}{l}\text { Dr Kingsford: specialists are a different type of doctor to a GP. I think } \\
\text { specialists know a lot about a certain case. They can be very bright in } \\
\text { one or two areas, but quite often they have no bedside manner at all ... I } \\
\text { mean, there's some very good specialists that are very good- like } \\
\text { psychiatrists, - that they can talk to people very well, but so many of } \\
\text { them are just technicians, purely technicians and very good technicians, } \\
\text { but very poor doctors. I've found this many times. }\end{array}$ \\
\hline
\end{tabular}

\section{DISCUSSION}

The most of the articles reviewed under this systematic review acknowledge the importance of using ethical principles in their day to day practice. A range of issues were encountered by the health care professionals in following the principles of ethics. Issues were more getting complicated when one principle was overridden by the other and this led to the confusion as what has to be followed. Disagreement between families and health care professionals, long waiting list, access to needed health care, informed consent and substitute decision making were viewed as the top ethical challenges in health care practice

\section{Research design}

Most of the research design used phenomenology, ethnography, Delphi method and grounded theory approach which is opt for the qualitative research. The assumption behind phenomenology is that there is an essence to shared experience. It comes from the social sciences and requires a researcher to enter into an individual's life world and use the self to interpret the individual or group experience. The goal of ethnographic research is to tell the whole story of a group's daily life, to identify the cultural meanings, beliefs and social patterns of the group. Grounded theory focus is on searching to identify the core social processes within a given social situation. ${ }^{2-9}$

\section{Research method}

The studies in this systematic review have utilized interview, observation and focus group discussion method which is most opt for qualitative research method.

\section{Sample size}

Malterud in his "Qualitative research: standards, challenges and guidelines" mentions that even though qualitative study utilizes small sample size because of the many varied sample and clinical situation assessed the study can be generalized to other clinical situations. ${ }^{8,9}$

\section{Sampling technique}

All the research studies used purposive sampling and it is justified that the purpose is interpretive explanation and not prediction of the conflicts and challenges of health care ethics. Hence it is most suitable for qualitative research. ${ }^{8,9}$

\section{Data analysis}

Most of the research used inductive reasoning approach in which we move from specific observation to broader generalizations and theories. Also called as bottom up approach. Theoretical concepts and relationship between the concepts have been explained. The research studies 
enhanced their validity by using two researchers reading, coding and comparing the finding of research. Few studies have also cross checked with the participants for the validity of the concepts they formed finally. ${ }^{2-9}$

Data revealed that the participants in the research studies encountered conflicts in adopting the universal ethical principles before coming to treatment decisions of the patient.

\section{Autonomy}

Autonomy is respecting patient's wishes or decisions about one's own body. The study done by Torjuul et al, Ebbesen et al, Jafarey et al is in line and agrees to respect patient decisions regarding treatment. In these studies health care professionals have expressed a dilemma in adopting the ethical principle when they think the patient's level of comprehension is compromised or in case of vulnerable patient's who is not able to decide on themselves or when the patient is terminally ill and is ready to accept any option the health care professionals suggest. And this is in line with the study done by Julie et al where the health care professionals have expressed the dilemma to accept patient or family wishes when the patient ability is compromised and in a study done by Hurst et al the participants said that they avoided the conflict by pretending to do what patient wanted. In a study done by Jafarey suggest that the doctor need to give sufficient time and consent should be taken at a level the patient can understand to his level of comprehension. When patient is terminally ill the other substitute decision makers should be consulted in taking decision about the patient treatment. Regarding the necessary information to be disclosed for consent the participants in the study done by Jafarey agree that true information should be disclosed while few participants have contradictory statement that sometimes it is better to use deceptive words. . $^{1,10-13}$

\section{Beneficience and non-maleficience}

The doctor's first and foremost duty is not to harm the patient the patient and next comes the beneficience. Torjuul and Ebbesen in their study have acknowledged the importance of beneficience whether it is clinical practice or research. In a study done by Julie et al the participants expressed the dilemma regarding the principle non malefficience wherein much medical procedure has both harmfull and beneficial effect on the patient. In the study done by Torjuul study indicate a dilemma of patient expectation versus duty of doctor where the patient walking with severe pain expects a miracle of cure as they cannot see the connection between treatment and illness. ${ }^{1,10,12}$ Mayer in his study his participants stressed the importance of accessibility of patients to the doctor and told that doctor may have to go out of the way to help patient, sometimes home visits in odd working hours. Participants felt that general practitioners are more comprehensive in assessing the patient need and specialists know lot certain case and sometimes are purely technicians. ${ }^{17}$

\section{Justice}

This principle suggest regardless of caste, creed and social status every individual should be treated equally. In a study done by Ebbesen et al the doctor's were in agreement to distribute the scarce resources available so as to provide treatment to as many patient's as possible. Residents in Julie study reported to compromise in telling the truth as they felt it could harm the patient. This involved them in manipulating information in many ways like delaying, framing or omitting information related to their treatment. ${ }^{1,12}$ They also concluded that trust is very important in doctor patient relationship and continuity of care for long term.

In few articles the participants have raised concern and dilemma related to the competences of the dentist, various managements strategies of the patients and importance of establishment of ethical consultations committees.

\section{Competences}

In a study done by Rosenbaum et al residents raised concerns about their own competence in handling patients. They were also concerned how their peers, attending physician and superiors perceived their competence. There was also tension of balancing their professional responsibility to challenge, intervene or report the inappropriate or inadequate behaviour of their colleagues. This was in line with the study done by Torjuul et al where in the respondents said that they cannot blame other person for the wrong that happens in treating patients. ${ }^{10,12}$

\section{Management of ethical practice}

In a study done by Agledalal et al focus on how doctors handle the moral aspects of the day-to-day clinical practice. In this the doctor used the process called clinical essential sing. The process consisted of breaking down the clinical situation into smaller units which are of manageable parts. The next approach was to concretize by objectifying the patient's descriptions and reach mutual understanding. The third approach was to categorize the patient's symptoms which could be entered into record and in an effort to focus the attention the doctor's took existential filtering. The next approach was the functional focus which draws the doctor's attention to benefiting patient's physical and mental function. Even though essentializing the doctor disregarded for the patient's private feelings their implicit clinical practice constantly emphasized the moral value of benefiting patient's physical and mental function. ${ }^{13}$ Nik-Sherina and Chirk-Jenn in their study explains the challenges of maintaining the family and professional role in treating family members. ${ }^{14}$ 


\section{Frequency of ethical conflicts and establishment of consultations}

A study done by Hurst reported that there is indeed a good frequency of encountering the ethical conflicts by health care professionals and by being aware of the ethical conflict help health care professionals to manage the ethical problem effectively. They suggested the importance of establishments of ethical consultation committee in the hospitals. Subjects also reported that when confronted with ethical difficulties the doctor looked for assistance may be from person involved with patient or whom he trusted. ${ }^{13}$

\section{Draw back}

Some researchers argue that synthesis of qualitative research on the grounds that concept identified in one setting is not applicable to others. This can be overcome by checking that each transfer is valid and understanding gained.

More over most of the investigations are done by the doctors themselves and hence are in a position to understand the terminologies and meanings of the clinical situations and thus minimizes the bias in the study.

\section{Recommendations}

1. Educating health care professionals- incorporating theory base ethical teaching to clinical based teaching. Making mandatory for health care professionals to update their knowledge though attending continuing medical education programme. Studies have shown that professionals justified the ethical issues more precisely after the intensive course on bioethics.

2. Establishing ethical consultative committee for advising when there is a disagreement or conflict with the case.

3. Examining the patient's ethical perspective in clinical situation.

\section{CONCLUSION}

Ethical issues in health care practice are many. Various factors autonomy, beneficence and other principles were considered by the health professionals to address the problem. Sometimes the issues are emotionally challenging since the one principle of ethics can be more important than the other. Getting sensitized and training by the health professional would help him to handle the clinical ethical situation better. Thus adding the quality to the clinical care.

Funding: No funding sources Conflict of interest: None declared Ethical approval: Not required

\section{REFERENCES}

1. Ebbesen M, Pedersen BD. Empirical investigation of the ethical reasoning of physicians and molecular biologists - the importance of the four principles of biomedical ethics. Am J Med. 2004;116:402-7.

2. Thomas J, Harden A. Methods for the thematic synthesis of qualitative research in systematic reviews. ESRC National Centre for Research Methods, NCRM Working Paper Series Number (10/07). Available at: http://eppi.ioe.ac.uk/cms/ Default.aspx?tabid=188. Accessed on 3 August 2017.

3. Rogers WA. Ethical issues in public health: a qualitative study of public health practice in Scotland. J Epidemiol Community Health. 2004;58:446-50.

4. Reis S, Biderman A, Mitki R, Borkan JM. Secrets in Primary Care: A Qualitative Exploration and Conceptual Model. J General Internal Med. 2007;22:1246-53.

5. Praestegaard J, Gard G. The perceptions of Danish physiotherapists on the ethical issues related to the physiotherapist patient relationship during the first session: a phenomenological approach. BMC Medical Ethics. 2011;12:21.

6. Butters KJ. A qualitative study of the ethical practice of newly graduated nurses working in mental health. A thesis presented in partial fulfilment of the requirements for the degree of Master of Philosophy in Nursing at Massey University. 2008.

7. Malek JI, Geller G, Sugarman J. Intensive course on health care professionals talking about cases in bioethics: the effect of an intensive course on health care professionals. J Med Ethics. 2000;26:131-6.

8. Marshall M. Sampling for qualitative research. Family Practice. 1996;13:522-5.

9. Sbaraini ASM. How to do a grounded theory study: a worked example of a study of dental practices. BMC Med Res Methodol. 2011;11:128.

10. Torjuul K, Nordam A, Sørlie V. Action ethical dilemmas in surgery: an interview study of practicing surgeons. BMC Med Ethics. 2005;6:7.

11. Jafarey AM, Farooqui A. Informed consent in the Pakistani milieu: the physician's perspective. J Med Ethics. 2005;31:93-6.

12. Rosenbaum JR, Bradley EH. Sources of Ethical Conflict in Medical Housestaff Training: A Qualitative Study. Am J Med. 2004;116:402-7.

13. Agledahl KM, Førde R, Wifstad A. Clinical essentialising: a qualitative study of doctors' medical and moral practice. Medicine, Health Care, and Philosophy. 2010;13(2):107-13.

14. Nik-Sherina H, Chirk-Jenn NG. Doctors treating family members: A qualitative study among primary care practitioners in a teaching hospital in Malaysia. Asia Pacific J Family Med. 2006;5(2):1-6. 
15. Hurst SA, Hull SC, DuVal G, Danis M. How physicians face ethical difficulties: a qualitative analysis. J Med Ethics. 2005;31:7-14.
Cite this article as: Kemparaj VM, Kadalur UG.

Understanding the principles of ethics in health care: a systematic analysis of qualitative information. Int $\mathbf{J}$ Community Med Public Health 2018;5:822-8. 